\title{
A family with Liddle's syndrome caused by a new c.1721 deletion mutation in the epithelial sodium channel $\beta$-subunit
}

\author{
XIA DING $^{1,2}$, NA JIA $^{1}$, CONG ZHAO $^{1}$, YOU ZHONG ${ }^{1}$, DAPENG DAI $^{3}$, YUANYUAN ZHAO ${ }^{4}$, \\ CHENGQI XU ${ }^{4}$, JIANPING CAI ${ }^{3}$, QING WANG ${ }^{4}$ and QING HE $^{1}$ \\ ${ }^{1}$ Department of Cardiology, Beijing Hospital, National Center of Gerontology, Beijing 100730; \\ ${ }^{2}$ Department of Nephrology, Beijing Tiantan Hospital, Capital Medical University, Beijing 100050; \\ ${ }^{3}$ The Key Laboratory of Geriatrics, Beijing Hospital and Beijing Institute of Geriatrics, Ministry of Health, \\ Beijing 100730; ${ }^{4}$ Human Genome Research Center and College of Life Science and Technology, \\ Huazhong University of Science and Technology, Wuhan, Hubei 430074, P.R. China
}

Received February 6, 2018; Accepted November 1, 2018

DOI: $10.3892 / \mathrm{etm} .2019 .7270$

\begin{abstract}
A 19-year-old male with early refractory hypertension, hypokalemia, serum potassium level of $3.4 \mathrm{mmol} / \mathrm{l}$ and hypoaldosteronemia was indicated in the present study. According to the results of laboratory tests and examinations, the patient was suspected of having Liddle's syndrome (LS). Genetic analysis of SCNN1B revealed a deletion mutation (c.1721delC). This mutation caused a length extension of SCNN1B coding sequence, which resulted in p.Pro574HisfsX675. A total of 34 family members were enrolled in the study and 29 of these family members underwent genetic testing. A total of 10 family members were clinically diagnosed with hypertension. Notably, 5 family members shared the same gene mutation as the proband and all cases with the mutation had hypertension. Blood pressure of the gene mutation carriers was well controlled by tailored treatment. In conclusion, a patient with early onset and refractory hypertension, hypokalemia and hypoaldosteronemia was diagnosed clinically and genetically with LS. Notably, a novel mutation (c.1721delC) was identified by DNA analysis. The present findings indicate that genetic analysis is useful, not only in the diagnosis of LS, but also in designing a tailored treatment.
\end{abstract}

Correspondence to: Dr Qing He, Department of Cardiology, Beijing Hospital, National Center of Gerontology, 1 Dahua Road, Beijing 100730, P.R. China

E-mail: heqingli2001@126.com

Abbreviations: LS, Liddle's syndrome; PCR, polymerase chain reaction; HRM, high resolution melting; PA, primary aldosteronism; $\mathrm{CAH}$, congenital adrenal hyperplasia; AME, apparent mineralocorticoid excess; RTA, renal tubular acidosis

Key words: Liddle's syndrome, hypertension, genetic diagnosis, epithelial sodium channel

\section{Introduction}

Liddle's syndrome (LS), first described by Liddle et al (1) in 1963, is characterized by high urinary potassium excretion, low urinary sodium excretion and maintained hypokalemia and volume expansion, resulting in hypertension and suppressed aldosterone excretion. Liddle hypothesized that excessive sodium reabsorption in the distal kidney tubules may be the reason for this clinical presentation. LS is a hereditary disease caused by mutations of epithelial sodium channels (ENaCs), which are located in kidney distal convoluted tubules. ENaCs are constructed by three homologous subunits. Each $\alpha-, \beta-$, $\gamma$-ENaC subunit has a highly conserved sequence termed the PY motif (Pro-Pro-Pro-X-Tyr motif) that serves as a binding site for Nedd4-2 in the process of ENaC ubiquitylation and endocytosis $(2,3)$. LS is genetically heterogeneous and arises from mutations in the cytoplasmic C-terminus of either the $\beta$ or $\gamma$ subunit of the amiloride-sensitive ENaC. Previous findings have indicated that mutations in the $\alpha$-subunit of ENaC genes are responsible for multisystem pseudohypoaldosteronism type 1 , which is a rare autosomal recessive aldosterone unresponsiveness syndrome (4). Mutations in the $\beta$ or $\gamma$ subunits of $\mathrm{ENaC}$ genes have been reported in a previous study and were strongly associated with LS (5). However, LS is a rare disease and can be easily overlooked or misdiagnosed. Hypertension caused by LS presents as refractory and hard to control. Inhibitors of sodium transport in the distal nephron, including amiloride and triamterene, are effective treatment options in patients with LS. Previous studies revealed that mineralocorticoid antagonists, including spironolactone, are not effective for patients with LS $(6,7)$.

In the present study, a young man presented with early-onset and refractory hypertension with hypokalemia and was clinically suspected of having LS. His pedigree was surveyed and molecular genetic studies were conducted.

\section{Materials and methods}

Clinical data. A 19-year-old male was admitted with early-onset hypertension and hypokalemia in June 2012 to 
the Department of Cardiology of Beijing Hospital (Beijing, China). The patient's medical history revealed 1 year of hypertension, with intermittent nausea and headache for 3 months. The patient had no history of blurred vision, chest tightness, chest pain, proteinuria, hematuria or edema. Furthermore, daily urine volume was normal. The basic metabolic panel revealed that potassium level was $3.4 \mathrm{mmol} / \mathrm{l}$. The patient was followed up routinely by clinic visits and phone calls for 3 years following the start of $5 \mathrm{mg}$ per day of amiloride treatment. In August 2015, the patient's clinical conditions were re-evaluated. A total of 34 family members were recruited to construct a pedigree. Clinical data were obtained from 29 family members. All family members provided oral informed consent prior to any procedure. Furthermore, the Ethics Committee of Beijing Hospital approved the present study.

Genetic diagnosis. Genetic analysis was performed on the proband and his family members. DNA was extracted from peripheral blood leukocytes using a TIANamp Blood DNA kit (Tiangen Biotech Co., Ltd., Beijing, China). The reference sequences of SCNN1B and SCNN1G were obtained from GenBank (https://www.ncbi.nlm.nih. gov/genbank/accession no. NM_000336.2 for SCNN1B and NM_001039.3 for SCNN1G). Primers were designed using Primer Premier 5.0 software (Premier Biosoft International, Palo Alto, CA, USA). All the exons of SCNN1B and SCNN1G were sequenced, but mutations were only identified in the last exon of SCNN1B. Polymerase chain reaction (PCR) was used to amplify the last exons of $\beta$ and $\gamma$ subunits of the $\mathrm{ENaC}$ based on the following primers: $\beta$, forward, 5 '-TGCTGTCCTCAT CGAGTTTG-3' and reverse, 5'-CCTCCACCAGCTCGGCCA CG-3'; and $\gamma$, forward, 5'-GCTTGGGTAGGAGGGAGA-3' and reverse, 5'-CCGTAAAGAGCTGCATCAG-3'. PCR products were purified using an Agarose Gel Purification kit (Beijing Biomed Gene Technology Co., Ltd., Beijing, China). All samples were sequenced in both forward and reverse directions with an Applied Biosystems 3730/3730x1 DNA Analyzers 3730 XL (Applied Biosystems; Thermo Fisher Scientific, Inc., Waltham, MA, USA).

High resolution melting (HRM) was used for detection of the mutation in other family members. Genotyping was performed using a SYTO9 fluorescent dye (Thermo Fisher Scientific, Inc.) and the HRM method on a Rotor-gene 6200 system (Qiagen, Inc., Valencia, CA, USA), according to the manufacturer's protocol. In brief, a short fragment containing the altered gene section was amplified with the forward primer 5'-TGCTGTGCCTCATCGAGTTTG-3' and a reverse primer of 3'-CCTCCACCAGCTCGGCCACG-5' using $5 \mu \mathrm{M}$ of SYTO9 fluorescent dye. Subsequently, the PCR products were genotyped using HRM analysis. DNA samples with known genotypes in the present pedigree were used as positive controls and $\mathrm{ddH}_{2} \mathrm{O}$ was used as a negative control.

In order to exclude single nucleotide polymorphisms induced by the gene change, HRM analysis was performed on 500 normal control DNA samples obtained from the Human Genome Research Center and College of Life Science and Technology of Huazhong University of Science and Technology (Wuhan, China).

\section{Results}

The proband had early onset hypertension with a blood pressure (BP) ranging from 140-230/80-140 $\mathrm{mmHg}$. The patient was asymptomatic when his BP was $<180 / 100 \mathrm{mmHg}$. Blood biochemistry parameters and urine tests were performed and plasma renin and aldosterone concentration, cortisol circadian rhythm, plasma catecholamine, and thyroid function were tested. Results indicated that potassium level was $3.4 \mathrm{mmol} / \mathrm{l}$ and plasma renin and aldosterone levels were normal while the subject was supine; however, these levels were suppressed while the subject was upright. Furthermore, renin and aldosterone levels decreased after the patient stood up. Detailed clinical data and positive auxiliary examination results of the proband (III-11) are presented in Table I. The results of parameters and tests not shown were all in the normal range. With the exception of BP, no abnormalities were detected on physical examination. Imaging was also normal, including imaging of the abdomen, renal artery and pituitary gland. Notably, hypertension was refractory following treatment with multiple drugs, including calcium channel blockers, angiotensin-converting-enzyme inhibitors, $\beta$-receptor blockers and diuretics. Based on the aforementioned data, LS was suggested as a potential diagnosis. A DNA sample from the patient was analyzed for detection of ENaC mutation. A novel deletion mutation (c.1721delC) was identified, which was suspected to be the cause of hypertension.

There were 34 members from three generations in the current pedigree. As indicated in Fig. 1, 29 family members were enrolled for genetic testing and the 4 family members could not be contacted and 1 family member was deceased. The clinical data of all members in this pedigree are presented in Table II. A total of 10/29 members in this pedigree were clinically diagnosed with hypertension. III-10 (sibling of the proband) was diagnosed with hypertension at the age of 20. Without regular treatment, the BP of III-10 fluctuated between $150-160 / 90-110 \mathrm{mmHg}$ and was poorly controlled. Furthermore, the subject's potassium level was $3.2 \mathrm{mmol} / 1$. In the proband's father's family, I-2, II-1, II-3 and II-5 (the proband's father) all developed hypertension in their $40 \mathrm{~s}$. In the proband's mother's family, I-4 was died as a result of cerebral vascular disease in her 70s. It was unknown whether this subject had hypertension because she had never received a physical examination. II-6 (the proband's mother) also exhibited early-onset hypertension at the age of 30. Her BP was $140 / 90 \mathrm{mmHg}$ and her potassium level was $3.5 \mathrm{mmol} / 1$. The maternal aunts of the proband (II-8, II-9) had presented with high BP at the same age as II-6, but without hypokalemia. The proband's cousin (III-16, son of II-8) had not been diagnosed with hypertension, but a random BP check revealed a BP of $140 / 100 \mathrm{mmHg}$ with a serum potassium level of $5.0 \mathrm{mmol} / 1$.

DNA sequencing revealed a deletion of cytosine at nucleotide 1721 of the coding DNA structure (c.1721delC) compared with the wild-type sequence in SCNN1B in the proband III-11, as indicated in Fig. 2. This deletion can cause a length extension of the SCNN1B coding sequence from 1,923 to 2,025 bp, leading to the modification of the open reading frame after the proline at position 574 and introduction of a new stop codon at position 675 (p.Pro574HisfsX675). Family members III-10, 
Table I. Clinical and biochemical characteristics of the proband III-11.

\begin{tabular}{lll}
\hline Characteristic & Proband III-11 & Normal value \\
\hline Sex & & Male \\
Age (years) & 20 \\
Age at onset of HTN (years) & 19 \\
BP before amiloride treatment (mmHg) & $230 / 130$ \\
Biochemical parameters & $3.5-5.0$ & \\
Serum potassium (mmol/l) & $135-145$ & 3.4 \\
Serum sodium (mmol/l) & $7-19 / 7-40$ & 136.2 \\
Plasma renin supine/upright $(\mathrm{pg} / \mathrm{ml})$ & $60-174 / 68-300$ & $17 / 16$ \\
Aldosterone supine/upright $(\mathrm{pg} / \mathrm{ml})$ & $34 / 44$ \\
Electrocardiogram & Sinus rhythm, LVHV \\
Echocardiogram & & LVPW, 13 mm; IVS, 12 mm; reduced LV diastolic function; \\
& & LVEF, 60\% \\
Fundus examination & & Retinal artery atherosclerosis in stage I \\
Nephrogram & & Normal size, slightly reduced GFR (left, 37.0 ml/min; right, \\
& & 33.7 ml/min)
\end{tabular}

Clinical data of the proband were collected in June 2012. The patient presented with high BP, low serum potassium, suppressed supine and upright plasma renin levels and plasma aldosterone. Cardiac tests indicated mild LV and IVS hypertrophy. Fundus examination and nephrogram results suggested mild HTN target-organ damage. HTN, hypertension; BP, blood pressure; LV, left ventricular; LVHV, left ventricular high voltage; LVPW, left ventricular posterior wall; IVS, interventricular septum; LVEF, left ventricular ejection fraction; GFR, glomerular filtration rate.

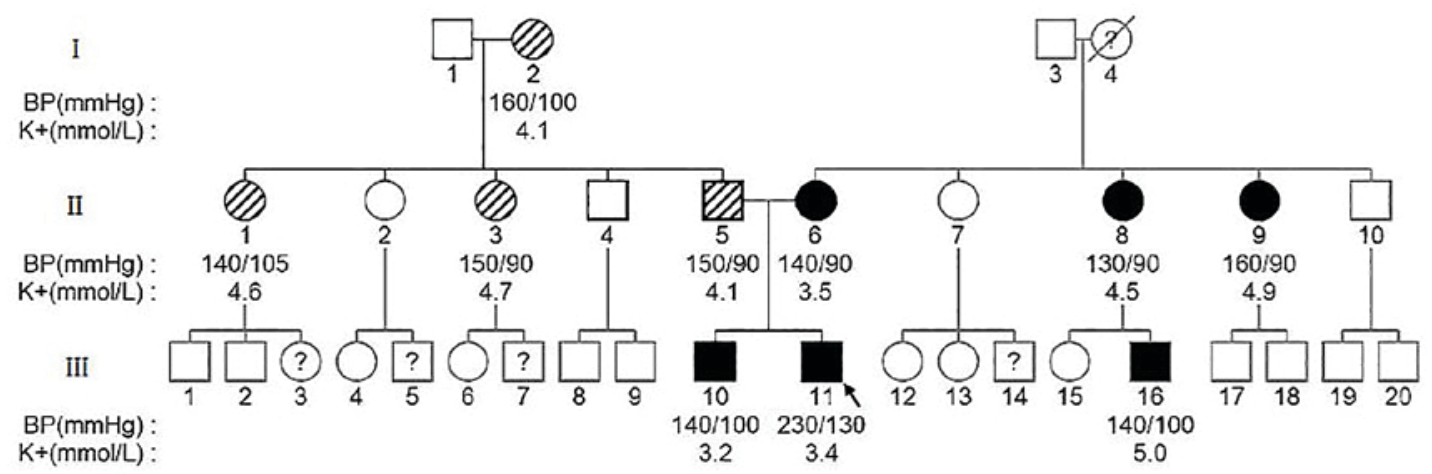

Figure 1. Genealogical tree of the family and DNA sequencing. There were 34 members from three generations in the pedigree. A total of 10/29 (4 hatched and 6 filled symbols) in this family were clinically diagnosed with hypertension. Squares indicate males and circles indicate females. I, II, III indicates different generations. Both hatched and filled symbols represent subjects with hypertension. Filled symbols represent subjects with the c.1721delC mutation. Unfilled symbols represent subjects with normal blood pressure. Deceased members are indicated with a diagonal line. The arrow indicates the proband (III-11). DNA sequencing analysis was performed in 29 individuals of this family. The gene mutation was identified in the proband and 5 other members (filled symbols) in this pedigree. The inheritance pattern of this mutation appeared to be autosomal dominant inheritance. Question marks indicate the family members who were not genetically diagnosed. BP, blood pressure; $\mathrm{K}^{+}$, serum potassium.

III-16, II-6, II-8, and II-9 shared the same mutation. However, no 1721 delC mutation was found in the other family members. No mutation of SCNN1G coding sequences was detected in the proband. The deletion mutation was identified in 6 people in the pedigree.

The HRM curve was compared between patients with and without c.1721delC mutation in the pedigree. The bimodal HRM curves of II-6, II-8, II-9 and III-10, who were discovered to be mutation carriers, are presented in Fig. 3. All other individuals involved in the study produced a unimodal curve.
Notably, HRM curves of III-11 and III-16 were not observed due to technical failure of extracting DNA. Furthermore, HRM analysis was performed on 500 normal control DNA samples. Smooth unimodal curves were shown in accordance with non-mutation carriers in this family.

Irbesartan, hydrochlorothiazide, spironolactone, amlodipine, bisoprolol and nifedipine treatment were all prescribed before LS was diagnosed; however, the proband's BP remained poorly controlled. After genetic testing, treatment was switched to amiloride and low-sodium diet 
Table II. Clinical data of the family members in the pedigree.

\begin{tabular}{|c|c|c|c|c|c|c|c|c|c|}
\hline Subject & Mutation & $\begin{array}{c}\text { Age } \\
\text { (years) }\end{array}$ & HTN & $\begin{array}{l}\text { Age of onset } \\
\text { of HTN (years) }\end{array}$ & $\begin{array}{c}\mathrm{BP} \\
(\mathrm{mmHg})\end{array}$ & $\begin{array}{c}\text { Medication } \\
\text { before amiloride }\end{array}$ & Comorbidity & $\begin{array}{c}\mathrm{K} \\
(\mathrm{mmol} / \mathrm{l})\end{array}$ & $\begin{array}{c}\mathrm{Na} \\
(\mathrm{mmol} / \mathrm{l})\end{array}$ \\
\hline $\mathrm{I}-1$ & No & 74 & UK & UK & $120 / 80,140 / 90$ & & CVD & 4.4 & 138.9 \\
\hline $\mathrm{I}-2$ & No & 75 & Yes & 74 & $160 / 100,150 / 80$ & & None & 4.1 & 142.3 \\
\hline I-3 & No & 74 & No & & $120 / 80,146 / 80$ & & None & 4.1 & 141.5 \\
\hline I-4 & UK & UK & UK & UK & UK & UK & UK & UK & UK \\
\hline II-1 & No & 49 & Yes & 46 & $140 / 105,160 / 100$ & $\begin{array}{l}\text { Reserpine, } \\
\text { captopril }\end{array}$ & None & 4.8 & 134.7 \\
\hline II-2 & No & 51 & No & & $130 / 90,130 / 80$ & & None & 4.6 & 138.5 \\
\hline II-3 & No & 46 & Yes & 46 & $125 / 85,150 / 90$ & Reserpine & None & 4.7 & 138.2 \\
\hline II-4 & No & 43 & No & & $120 / 80,130 / 90$ & & $\mathrm{~T} 2 \mathrm{DM}$ & 4.4 & 137.5 \\
\hline II-5 & No & 44 & Yes & 42 & $130 / 90,144 / 100$ & $\begin{array}{l}\text { Nifedipine, } \\
\text { enalapril }\end{array}$ & None & 4.1 & 141.0 \\
\hline II-6 & Yes & 55 & Yes & 30 & $140 / 90,156 / 80$ & $\begin{array}{l}\text { Nifedipine, } \\
\text { reserpine }\end{array}$ & None & 4.6 & 137.0 \\
\hline II-7 & No & 55 & No & & $120 / 80,150 / 90$ & & None & 4.6 & 137.0 \\
\hline II-8 & Yes & 50 & Yes & 30 & $130 / 90,150 / 100$ & $\begin{array}{l}\text { Nifedipine, } \\
\text { reserpine }\end{array}$ & None & 4.5 & 137.1 \\
\hline II-9 & Yes & 48 & Yes & 30 & $130 / 90,150 / 100$ & $\begin{array}{l}\text { Nifedipine, } \\
\text { amiloride }\end{array}$ & None & 4.9 & 138.8 \\
\hline II-10 & No & 45 & No & & $120 / 80,120 / 70$ & & None & 4.6 & 139.5 \\
\hline III-1 & No & 23 & No & & $120 / 80,124 / 100$ & & None & UK & UK \\
\hline III-2 & No & 25 & No & & $124 / 60,110 / 80$ & & None & UK & 122.9 \\
\hline III-4 & No & 27 & No & & $110 / 70,120 / 70$ & & None & 4.0 & 142.0 \\
\hline III-6 & No & 26 & No & & $120 / 80,120 / 80$ & & None & 3.9 & 140.0 \\
\hline III-8 & No & 20 & No & & $146 / 90,140 / 90$ & & None & 4.8 & 142.0 \\
\hline III-9 & No & 14 & No & & $120 / 78,110 / 70$ & & None & 4.6 & 140.0 \\
\hline III-10 & Yes & 21 & Yes & 19 & $150 / 100,160 / 110$ & & None & 3.2 & 142.8 \\
\hline III-11 & Yes & 22 & Yes & 20 & $150 / 110,150 / 90$ & $\begin{array}{l}\text { Irregular } \\
\text { medication }\end{array}$ & None & 3.4 & 136.2 \\
\hline III-12 & No & 28 & No & & $110 / 60,104 / 62$ & & None & 4.1 & 138.0 \\
\hline III-13 & No & 33 & No & & $130 / 80,124 / 80$ & & None & 4.2 & 143.0 \\
\hline III-15 & No & 24 & No & & $100 / 86,130 / 80$ & & None & 3.6 & 141.0 \\
\hline III-16 & Yes & 25 & Yes & 25 & $140 / 100,150 / 100$ & & None & 5.0 & 141.4 \\
\hline III-17 & No & 21 & No & & $124 / 86,130 / 80$ & & None & 4.6 & 142.0 \\
\hline III-18 & No & 25 & No & & $134 / 90,120 / 90$ & & None & 4.8 & 141.1 \\
\hline III-19 & No & 24 & No & & $140 / 90,130 / 80$ & & None & 4.2 & 142.0 \\
\hline III-20 & No & 21 & No & & $124 / 80,134 / 80$ & & None & 5.4 & 139.9 \\
\hline
\end{tabular}

Brief clinical history and blood biochemical parameters of 29 individuals in this family are shown in the table above. BP was measured on two different days. Among the family members, 10/29 were clinically diagnosed with HTN and 5 of them shared the same gene mutation with III-11. All gene mutation carriers had early onset hypertension with onset age from 20-30 years old. Mutation carriers III-10 and III-11 had hypokalemia, while the remaining five carriers had normal serum potassium. HTN, hypertension; BP, blood pressure; UK, unknown; Na, serum sodium; K, serum potassium; CVD, cerebrovascular disease; T2DM, type 2 diabetes.

( $2 \mathrm{~g} \mathrm{NaCl} /$ day). BP was gradually decreased to $110 / 80 \mathrm{mmHg}$ and potassium level increased to $4.4 \mathrm{mmol} / \mathrm{l}$ after 4 weeks of treatment. The proband was followed up with phone calls and re-evaluated after amiloride treatment for 3 years. BP was successfully controlled at the 3-year follow up. The patient's left ventricular hypertrophy (LVH), fundus artery and kidney function was improved at his second evaluation, as indicated in Table III. Notably, family members II-6, II-8,
II-9 and III-10 also had their BP controlled by amiloride therapy.

Comparison of the proband's clinical data and auxiliary examination results before and after amiloride treatment for 3 years revealed an improvement in the proband's condition: High BP was decreased to a normal range, serum potassium was increased, and LVH and fundus conditions were improved. 
Table III. Clinical data for the proband before and after amiloride treatment for 3 years.

\begin{tabular}{lll}
\hline Variable & \multicolumn{1}{c}{ Before amiloride } & \multicolumn{1}{c}{ After amiloride } \\
\hline Mean BP (mmHg) & $153 / 102$ & $129 / 69$ \\
Serum potassium (mmol/l) & 3.4 & 3.6 \\
Echocardiogram & IVS, $12 \mathrm{~mm} ;$ PWT, $13 \mathrm{~mm} ; \mathrm{LVID}, 53 \mathrm{~mm} ;$ & IVS, $11 \mathrm{~mm} ;$ PWT, $11 \mathrm{~mm} ; \mathrm{LVID}, 48 \mathrm{~mm} ;$ \\
& LVEDV, $135 \mathrm{ml}$ & LVEDV, $108 \mathrm{ml}$ \\
$24 \mathrm{~h}$ urine protein $(\mathrm{g} / 24 \mathrm{~h})$ & 0.10 & 0.09 \\
GFR & Left, $37.0 \mathrm{ml} / \mathrm{min}$; right, $33.7 \mathrm{ml} / \mathrm{min}$ & Left, $45.5 \mathrm{ml} / \mathrm{min}$; right, $49.8 \mathrm{ml} / \mathrm{min}$ \\
Fundus examination & Retinal artery atherosclerosis in stage I & No retinal artery atherosclerosis
\end{tabular}

Comparison of the proband's clinical data and auxiliary examination results before and after amiloride treatment for 3 years. The results indicate improvement of the proband's condition: High BP decreased to normal range, serum potassium increased, and there was improvement in LV and IVS hypertrophy, as well as to organ damage in the kidney and fundus. BP, blood pressure; LV, left ventricular; LVID, LV internal diameter; LVEDV, LV end diastolic volume; IVS, interventricular septum; PWT, posterior wall thickness.
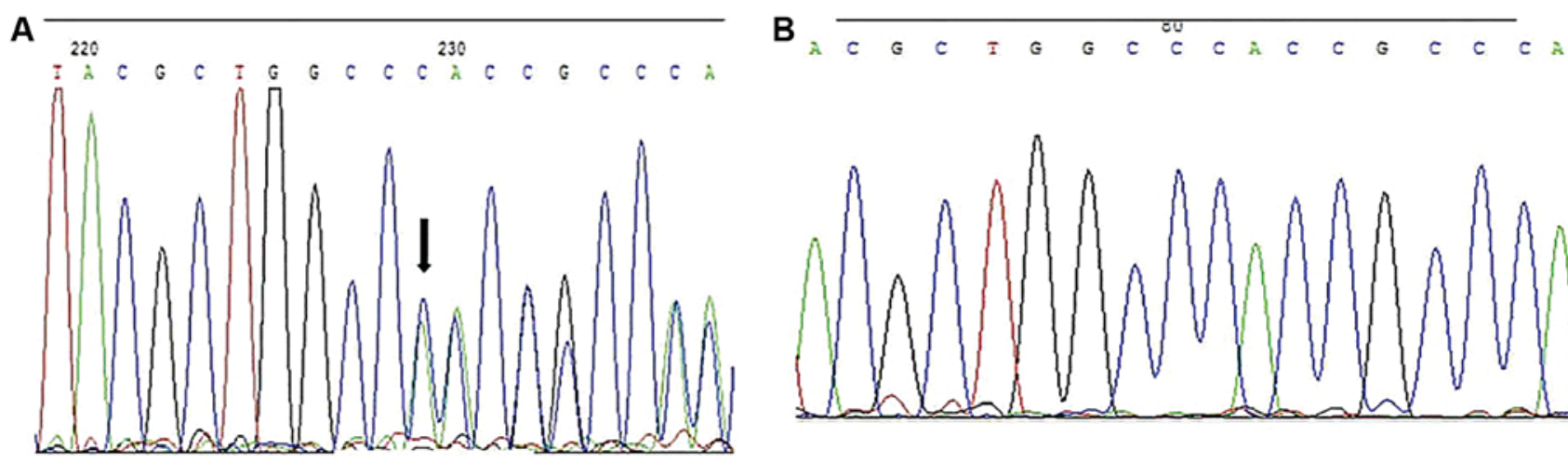

Figure 2. DNA sequence analysis of SCNN1B in the proband (III-11) and a normal control. The black arrow indicates that both C and A signals were observed. (A) DNA sequence of the sense strand revealed a deletion of a cytosine at nucleotide 1721 of the coding DNA structure compared with the wild-type sequence of SCNN1B. (B) Wild-type sequence of SCNN1B. The deletion in A modified the open reading frame after the proline in position 574 and introduced a new stop codon at position 675 (p.Pro574HisfsX675).

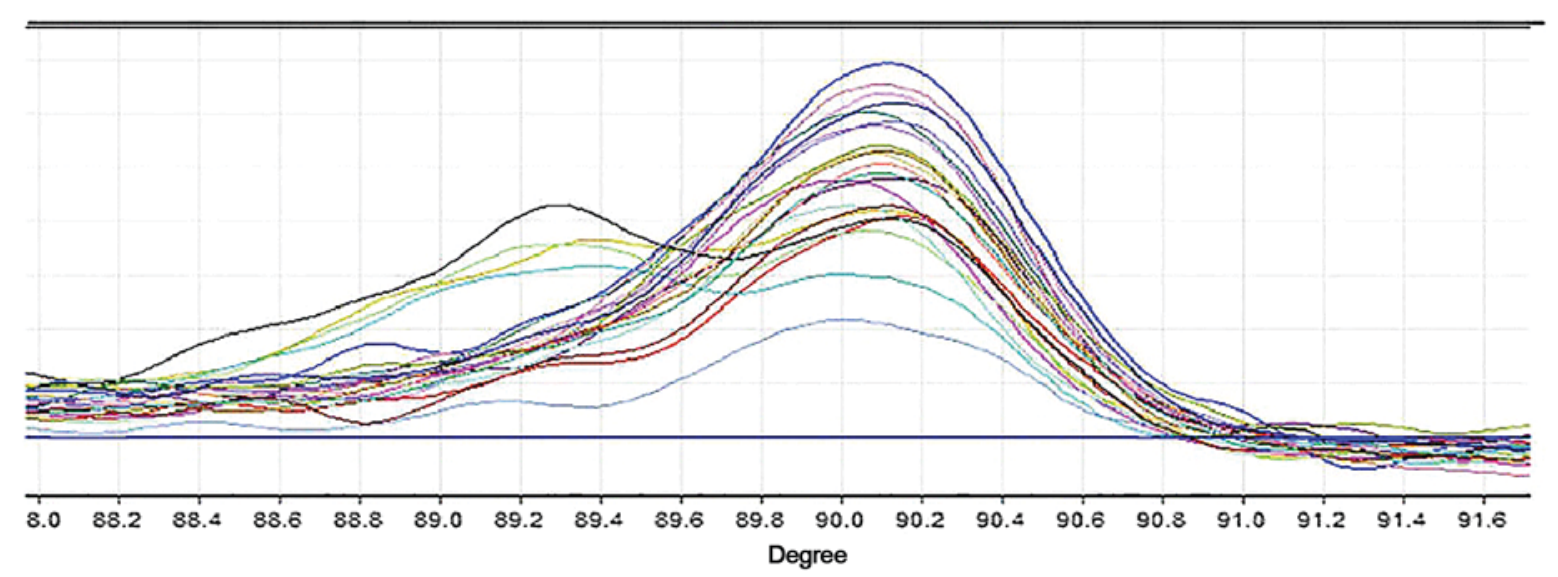

Figure 3. Comparison of HRM analysis between patients with mutation carriers and normal controls. The bimodal HRM curves of II-6, II-8, II-9 and III-10, patients who were discovered to be mutation carriers, are indicated. All other individuals involved in this study produced a unimodal curve. HRM analysis was also performed on 500 normal control DNA samples. Smooth unimodal curves were observed in accordance with non-mutation carriers in this family. HRM, high resolution melting.

\section{Discussion}

In 1994, LS was confirmed by the discovery of a molecular defect that was an activating mutation in the subunit of
$\mathrm{ENaC}$ (8). Numerous mutations in $\mathrm{ENaC}$ have now been reported (Table IV) (8-28). The majority of these were missense mutations, but deletion and insertion mutations have also been reported. Regardless of the mutation in SCNN1B and 
Table IV. Mutations in $\beta$ and $\gamma$ subunits of epithelial sodium channel identified in Liddle's syndrome.

A, Mutations in SCNN1B

\begin{tabular}{|c|c|c|c|c|c|}
\hline Author, year & Mutation $^{\mathrm{a}}$ & Consequence $^{\mathrm{b}}$ & Phenotype $^{c}$ & Initially termed $^{\mathrm{d}}$ & (Refs.) \\
\hline Rayner et al, 2003 & c. $1688 \mathrm{G}>\mathrm{A}$ & p.Arg563Gln & $\mathrm{HT}, \mathrm{R} \downarrow, \mathrm{A} \downarrow, \mathrm{K} \downarrow$ & p.Arg563Gln & (9) \\
\hline $\begin{array}{l}\text { Schild et al, 1995; } \\
\text { Shimkets et al, } 1994\end{array}$ & c. $1696 \mathrm{C}>\mathrm{T}$ & p.Arg566X & $\mathrm{HT}, \mathrm{R} \downarrow, \mathrm{A} \downarrow, \mathrm{K} \downarrow, \mathrm{SD}$ & p.Arg 564X & $(10,11)$ \\
\hline Gong et al, 2014 & c. $1698 \mathrm{C}>\mathrm{T}$ & p.Arg566X & $\mathrm{HT}, \mathrm{R} \downarrow, \mathrm{A} \downarrow, \mathrm{K} \downarrow$ & p.Arg 566X & (12) \\
\hline Jeunemaitre et al, 1997 & c.1735_1766del32 & p.Ala579LeufsX582 & $\mathrm{HT}, \mathrm{R} \downarrow, \mathrm{A} \downarrow, \mathrm{K} \downarrow, \mathrm{SD}$ & p.Ala579_589Glydel & (13) \\
\hline Shimkets et al, 1994 & c. $1771 \mathrm{C}>\mathrm{T}$ & p.Arg591X & $\mathrm{HT}, \mathrm{R} \downarrow, \mathrm{A} \downarrow, \mathrm{K} \downarrow$ & p.Gln $589 X$ & $(11)$ \\
\hline Shimkets et al, 1994 & c.1781dupC & p.Thr594HisfsX607 & $\mathrm{HT}, \mathrm{R} \downarrow, \mathrm{A} \downarrow, \mathrm{K} \downarrow$ & p.Thr592ThrfsX605 & (11) \\
\hline Gong et al, 2014 & c.1784_1789insC & p.Arg597ProfsX607 & $\mathrm{HT}, \mathrm{R} \downarrow, \mathrm{A} \downarrow, \mathrm{K} \downarrow$ & p.Arg 597ProfrX607 & (12) \\
\hline Shimkets et al, 1994 & c.1789delC & p.Arg597AlafsX675 & $\mathrm{HT}, \mathrm{R} \downarrow, \mathrm{A} \downarrow, \mathrm{K} \downarrow$ & p.Arg595AlafsX673 & (11) \\
\hline $\begin{array}{l}\text { Jackson et al, 1998; } \\
\text { Nakano et al, } 2002\end{array}$ & c.1789dupC & p.Arg597ProfsX607 & $\mathrm{HT}, \mathrm{R} \downarrow, \mathrm{A} \downarrow, \mathrm{K} \downarrow$ & p.Arg595ProfsX605 & $(14,15)$ \\
\hline $\begin{array}{l}\text { Hiltunen et al, 2002; } \\
\text { Ma et al, } 2001\end{array}$ & c.1800_1801insG & p.Thr601AspfsX607 & $\mathrm{HT}, \mathrm{R} \downarrow, \mathrm{A} \downarrow, \mathrm{K} \downarrow$ & p.Thr601AspfsX607 & $(16,17)$ \\
\hline Sawathiparnich et al, 2009 & c. $1850 \mathrm{C}>\mathrm{A}$ & p.Pro617His & $\mathrm{HT}, \mathrm{R} \downarrow, \mathrm{A} \downarrow$ & p.Pro615His & (18) \\
\hline Uehara et al, 1998 & c. $1852 \mathrm{C}>\mathrm{T}$ & p.Pro618Ser & $\mathrm{HT}, \mathrm{R} \downarrow, \mathrm{A} \downarrow, \mathrm{K} \downarrow$ & p.Pro616Ser & (19) \\
\hline Hansson et al, 1995 & c. $1853 \mathrm{C}>\mathrm{T}$ & p.Pro618Leu & $\mathrm{HT}, \mathrm{R} \downarrow, \mathrm{A} \downarrow, \mathrm{K} \downarrow, \mathrm{SD}$ & p.Pro616Leu & (20) \\
\hline Wang et al, 2012 & c. $1853 \mathrm{C}>\mathrm{A}$ & p.Pro618His & $\mathrm{HT}, \mathrm{R} \downarrow, \mathrm{A} \downarrow, \mathrm{K} \downarrow$ & p.Pro616Ser & $(21)$ \\
\hline Furuhashi et al, 2005 & c. $1853 \mathrm{C}>\mathrm{G}$ & p.Pro618Arg & $\mathrm{HT}, \mathrm{R} \downarrow, \mathrm{A} \downarrow, \mathrm{K} \downarrow$ & p.Pro616Arg & $(22)$ \\
\hline Yang et al, 2015 & c.1854dupC & p.Asn619GlnfsX621 & $\mathrm{HT}, \mathrm{R} \downarrow, \mathrm{A} \downarrow, \mathrm{K} \downarrow$ & p.Asn619GlnfsX3 & (23) \\
\hline Tamura et al, 1996 & c. $1858 \mathrm{~T}>\mathrm{C}$ & p.Try620His & $\mathrm{HT}, \mathrm{R} \downarrow, \mathrm{A} \downarrow, \mathrm{K} \downarrow$ & p.Try618His & (24) \\
\hline Present study & c.1721delC & p.Pro574HisfsX675 & $\mathrm{HT}, \mathrm{R} \downarrow, \mathrm{A} \downarrow, \mathrm{K} \downarrow$ & & - \\
\hline
\end{tabular}

B, Mutations in SCNN1G

\begin{tabular}{|c|c|c|c|c|c|}
\hline Author, year & Mutation $^{\mathrm{a}}$ & Consequence $^{\mathrm{b}}$ & Phenotype $^{c}$ & Initially termed $^{\mathrm{d}}$ & (Refs.) \\
\hline Hiltunen et al, 2002 & c. $1589 A>G$ & p.Asn530Ser & $\mathrm{HT}, \mathrm{R} \downarrow, \mathrm{A} \downarrow, \mathrm{K} \downarrow$ & p.Asn530Ser & (16) \\
\hline Shi et al, 2010 & c. $1699 \mathrm{C}>\mathrm{T}$ & p.Gln567X & $\mathrm{HT}, \mathrm{R} \downarrow, \mathrm{A} \downarrow, \mathrm{K} \downarrow$ & p.Gln567X & $(25)$ \\
\hline Hansson et al, 1995 & c. $1718 \mathrm{G}>\mathrm{A}$ & p.Trp573X & $\mathrm{HT}, \mathrm{R} \downarrow, \mathrm{A} \downarrow, \mathrm{K} \downarrow$ & p.Trp574X & (26) \\
\hline Yamashita et al, 2001 & c. $1724 \mathrm{G}>\mathrm{A}$ & p.Trp575X & $\mathrm{HT}, \mathrm{R} \downarrow, \mathrm{A} \downarrow, \mathrm{K} \downarrow$ & p.Trp576X & $(27)$ \\
\hline Wang et al, 2007 & c.1749_1753del5 & p.Glu583GlufsX585 & $\mathrm{HT}, \mathrm{R} \downarrow, \mathrm{A} \downarrow, \mathrm{K} \downarrow$ & p.Glu583GlufsX585 & (28) \\
\hline
\end{tabular}

${ }^{\mathrm{a}}$ Gene position of SCNN1B and SCNN1G is according to the reference sequences NM_000336.2 and NM_001039.3 in GenBank. A of the ATG translation initiation codon was denoted as nucleotide $1 .{ }^{b}$ Consequence is according to NP_000327.2 and NP_001030.2 in GenBank. ${ }^{\mathrm{c}} \mathrm{Clinical}$ manifestations in patients with LS. ${ }^{\mathrm{d}}$ Term used to describe mutation in source article. fs, frameshift; HT, hypertension; R $\downarrow$, low plasma renin activity; $\mathrm{A} \downarrow$, low plasma aldosterone; $\mathrm{K} \downarrow$, low plasma $\mathrm{K}+$ levels; SD, sudden death.

SCNN1G, a frameshift mutation may cause the LS phenotype. Genetic defects frequently affect a highly conserved sequence known as the PY motif (starting from p.616 in SCNN1B and p.623 in SCNN1G), which serves as a binding site for Nedd4-2. Nedd4-2 acts as a bridge that connects the PY motif of the $\mathrm{ENaC}$ at one side and combines with ubiquitin ligase on the other side. Notably, ubiquitylation is important for degradation of the $\mathrm{ENaC}$ to maintain a constant number of ENaCs. In the process of $\mathrm{ENaC}$ ubiquitylation and endocytosis, the mutated PY motif fails to bind with Nedd4-2, resulting in an excessive number and overactivation of ENaCs on the cell surface, which leads to an increase of sodium and fluid absorption in the distal convoluted tubules (29).
The proband in the current case was characterized by early-onset refractory hypertension with features of familial aggregation. For this patient, signs of primary aldosteronism (PA) were looked for based on his hypertension and hypokalemia, but no mass was found in the adrenal gland. The Endocrinology Society guidelines recommend the use of aldosterone-to-renin ratio as the most reliable test for detecting PA (30). Notably, the levels of renin in the current patient were very low without hyperaldosteronemia and serum aldosterone was low. For the present case there were several other possibilities, including congenital adrenal hyperplasia (CAH), apparent mineralocorticoid excess (AME), LS and renal tubular acidosis (RTA) (31). CAH is a group of 
autosomal recessive disorders encompassing enzyme deficiencies in the adrenal steroidogenesis pathway, which lead to impaired cortisol biosynthesis. A lack of $17 \alpha$-hydroxylase and 21-hydroxylase is the most common type of $\mathrm{CAH}$, which can lead to notable sex character changes, including masculinization, precocious puberty and testicular tumors $(32,33)$. AME is a syndrome associated with the absence or impaired activity of the enzyme 11 $\beta$-hydroxysteroid dehydrogenase (34). Diagnosis relies on a triad of hypertension, hypokalemia and suppressed plasma aldosterone levels, plus an abnormal urinary cortisol to cortisone ratio and electrolyte disturbance (34). It is difficult to differentiate from LS in certain cases. However, AME patients are normally sensitive to spironolactone treatment. Furthermore, certain RTA patients can present with hypertension and hypokalemia, but their symptoms are often accompanied with other features, including dehydration, obtundation, restricted skeletal growth and urinary tract stones. Such cases are usually detected in infancy. However, milder versions of the disease typically present later in childhood (35). All of the clinical features and auxiliary examination results in the present case indicated the possibility of LS. The genetic diagnosis for LS is an indispensable method alongside typical clinical presentation. Genetic analysis of the current case indicated a mutated $\beta \mathrm{ENaC}$ subunit, c.1721delC, which was located before the PY coding sequence, and caused a length extension of SCNN1B coding sequence from 1,923 to 2,025 bp. This may affect the combination of Nedd4-2 and the ubiquitylation of ENaC. This mutation was also detected in 5 other family members who presented with hypertension in early adulthood. A notable finding of the present study was that hypokalemia was only present in the proband's immediate family, but not in other mutation carriers. This result indicated that differences of penetrance are possible, even in the same pedigree and among carriers of the same mutation. Furthermore, the present results revealed that the mutation had an autosomal dominant inheritance pattern and presented with features of pedigree co-segregation.

Treatment for LS includes a sodium-restricted diet, inhibition of ENaCs and potassium supplementation. Amiloride is a typical $\mathrm{ENaC}$ inhibitor, which combines with $\mathrm{ENaCs}$ before the PY motif site to block the ENaC. By inhibiting $\mathrm{Na}^{+}-\mathrm{K}^{+}$ exchange and $\mathrm{Na}^{+}-\mathrm{H}^{+}$exchange, amiloride can alleviate sodium and water retention to further improve hypertension and hypokalemia. In the current case, the patient had poorly controlled BP with a range of 140-220/80-140 $\mathrm{mmHg}$ and had developed gingival hyperplasia subsequent to high doses of nifedipine. However, after single amiloride treatment for 3 years, BP was well controlled and end-organ damage had been reversed. The antihypertensive benefit of amiloride for LS was also verified in other family members who carried the same mutation, providing further supporting evidence for the diagnosis of LS.

In conclusion, a patient with LS was diagnosed clinically and genetically in the present study. The patient's clinical presentation included early onset and refractory hypertension, familial aggregation, hypokalemia and hypoaldosteronemia. To the best of our knowledge, the deletion mutation (c.1721delC) has not been reported in previous literature. The present findings indicated that genetic analysis is helpful in the diagnosis of hypertension in a patient who is clinically suspected of
LS. Furthermore, the results suggested that it is also useful to screen the proband's family members. These findings demonstrate the benefits of genetic testing and tailored treatment.

\section{Acknowledgements}

Not applicable.

\section{Funding}

No funding was received.

\section{Availability of data and materials}

The datasets used and/or analyzed during the present study are available from the corresponding author on reasonable request.

\section{Authors' contributions}

$\mathrm{XD}$ and $\mathrm{CZ}$ acquired or analyzed data. NJ assisted in data collection and analysis. YZ and $\mathrm{QH}$ designed the current study and performed follow up. DD designed the experiments and performed genetic testing. YZ and CX performed genetic testing and HRM analysis. JC and QW also designed the experiments of the current study and performed genetic testing.

\section{Ethics approval and consent to participate}

The present study was approved by the Ethics Committee of Beijing Hospital (Beijing, China).

\section{Patient consent for publication}

All family members provided oral informed consent prior to publication.

\section{Competing interests}

The authors declare that they have no competing interests.

\section{References}

1. Liddle GW, Bledsoe T and Coppage WS: A familial renal disorder simulating primary aldosteronism but with negligible aldosterone secretion. Trans Assoc Am Physicians 76: 199-213, 1963.

2. Canessa CM, Schild L, Buell G, Thorens B, Gautschi I, Horisberger JD and Rossier BC: Amiloride-sensitive epithelial $\mathrm{Na}+$ channel is made of three homologous subunits. Nature 367: 463-467, 1994.

3. Schild L: The ENaC channel as the primary determinant of two human diseases: Liddle syndrome and pseudohypoaldosteronism. Nephrologie 17: 395-400, 1996.

4. Edelheit O, Hanukoglu I, Gizewska M, Kandemir N, Tenenbaum-Rakover Y, Yurdakök M,Zajaczek S and Hanukoglu A: Novel mutations in epithelial sodium channel (ENaC) subunit genes and phenotypic expression of multisystem pseudohypoaldosteronism. Clin Endocrinol (Oxf) 62: 547-553, 2005.

5. Schild L, Lu Y, Gautschi I, Schneeberger E, Lifton RP and Rossier BC: Identification of a PY motif in the epithelial Na channel subunits as a target sequence for mutations causing channel activation found in Liddle syndrome. EMBO J 15: 2381-2387, 1996.

6. Yang KQ, Xiao Y, Tian T, Gao LG and Zhou XL: Molecular genetics of Liddle's syndrome. Clin Chim Acta 436: 202-206, 2014. 
7. Zhou R, Patel SV and Snyder PM: Nedd4-2 catalyzes ubiquitination and degradation of cell surface ENaC. J Biol Chem 282: 20207-20212, 2007.

8. Botero-Velez M, Curtis JJ and Warnock DG: Brief report: Liddle's syndrome revisited-a disorder of sodium reabsorption in the distal tubule. N Engl J Med 330: 178-181, 1994.

9. Rayner BL, Owen EP, King JA, Soule SG, Vreede H, Opie LH, Marais D and Davidson JS: A new mutation, R563Q, of the beta subunit of the epithelial sodium channel associated with low-renin, low-aldosterone hypertension. J Hypertens 21: 921-926, 2003.

10. Schild L, Canessa CM, Shimkets RA, Gautschi I, Lifton RP and Rossier BC: A mutation in the epithelial sodium channel causing Liddle disease increases channel activity in the Xenopus laevis oocyte expression system. Proc Natl Acad Sci USA 92: 5699-5703, 1995.

11. Shimkets RA, Warnock DG, Bositis CM, Nelson-Williams C, Hansson JH, Schambelan M, Gill JR Jr, Ulick S, Milora RV, Findling JW, et al: Liddle's syndrome: Heritable human hypertension caused by mutations in the beta subunit of the epithelial sodium channel. Cell 79: 407-414, 1994.

12. Gong L, Chen J, Shao L, Song W, Hui R and Wang Y: Phenotype-genotype analysis in two Chinese families with Liddle syndrome. Mol Biol Rep 41: 1569-1575, 2014.

13. Jeunemaitre X, Bassilana F, Persu A, Dumont C, Champigny G, Lazdunski M, Corvol P and Barbry P: Genotype-phenotype analysis of a newly discovered family with Liddle's syndrome. J Hypertens 15: 1091-1100, 1997.

14. Jackson SN, Williams B, Houtman P and Trembath RC: The diagnosis of Liddle syndrome by identification of a mutation in the beta subunit of the epithelial sodium channel. J Med Genet 35: 510-512, 1998

15. Nakano Y, Ishida T, Ozono R, Matsuura H, Yamamoto $Y$, Kambe M, Chayama K and Oshima T: A frameshift mutation of beta subunit of epithelial sodium channel in a case of isolated Liddle syndrome. J Hypertens 20: 2379-2382, 2002.

16. Hiltunen TP, Hannila-Handelberg T, Petäjäniemi N, Kantola I, Tikkanen I, Virtamo J, Gautschi I, Schild L and Kontula K: Liddle's syndrome associated with a point mutation in the extracellular domain of the epithelial sodium channel gamma subunit. J Hypertens 20: 2383-2390, 2002.

17. Ma X, Tian Y, Gao Y and Guo X: A study of mutation(s) of the epithelial sodium channel gene in a Liddle's syndrome family. Zhonghua Nei Ke Za Zhi 40: 390-393, 2001 (In Chinese).

18. Sawathiparnich P, Sumboonnanonda A, Weerakulwattana P and Limwongse C: A novel mutation in the beta-subunit of the epithelial sodium channel gene (SCNN1B) in a Thai family with Liddle's syndrome. J Pediatr Endocrinol Metab 22: 85-89, 2009.

19. Uehara Y, Sasaguri M, Kinoshita A, Tsuji E, Kiyose H, Taniguchi $\mathrm{H}$, Noda $\mathrm{K}$, Ideishi M, Inoue J, Tomita K and Arakawa K: Genetic analysis of the epithelial sodium channel in Liddle's syndrome. J Hypertens 16: 1131-1135, 1998.

20. Hansson JH, Schild L, Lu Y, Wilson TA, Gautschi I, Shimkets R, Nelson-Williams C, Rossier BC and Lifton RP: A de novo missense mutation of the beta subunit of the epithelial sodium channel causes hypertension and Liddle syndrome, identifying a proline-rich segment critical for regulation of channel activity. Proc Natl Acad Sci USA 92: 11495-11499, 1995.
21. Wang LP, Gao LG, Zhou XL, Wu HY, Zhang L, Wen D, Li YH, Liu YX, Tian T, Fan XH, et al: Genetic diagnosis of Liddle's syndrome by mutation analysis of SCNN1B and SCNN1G in a Chinese family. Chin Med J (Engl) 125: 1401-1404, 2012.

22. Furuhashi M, Kitamura K, Adachi M, Miyoshi T, Wakida N, Ura N, Shikano Y, Shinshi Y, Sakamoto K, Hayashi M, et al: Liddle's syndrome caused by a novel mutation in the proline-rich PY motif of the epithelial sodium channel beta-subunit. J Clin Endocrinol Metab 90: 340-344, 2005.

23. Yang KQ, Lu CX, Xiao Y, Liu YX, Jiang XJ, Zhang $X$ and Zhou XL: A novel frameshift mutation of epithelial sodium channel $\beta$-subunit leads to Liddle syndrome in an isolated case. Clin Endocrinol (Oxf) 82: 611-614, 2015.

24. Tamura H, Schild L, Enomoto N, Matsui N, Marumo F and Rossier BC: Liddle disease caused by a missense mutation of beta subunit of the epithelial sodium channel gene. J Clin Invest 97: 1780-1784, 1996 .

25. Shi JY, Chen X, Ren Y, Long Y and Tian HM: Liddle's syndrome caused by a novel mutation of the gamma-subunit of epithelial sodium channel gene SCNN1G in Chinese. Zhonghua Yi Xue Yi Chuan Xue Za Zhi 27: 132-135, 2010 (In Chinese).

26. Hansson JH, Nelson-Williams C, Suzuki H, Schild L, Shimkets R, Lu Y, Canessa C, Iwasaki T, Rossier B and Lifton RP: Hypertension caused by a truncated epithelial sodium channel gamma subunit: Genetic heterogeneity of Liddle syndrome. Nat Genet 11: 76-82, 1995.

27. Yamashita Y, Koga M, Takeda Y, Enomoto N, Uchida S, Hashimoto K, Yamano S, Dohi K, Marumo F and Sasaki S: Two sporadic cases of Liddle's syndrome caused by De novo ENaC mutations. Am J Kidney Dis 37: 499-504, 2001.

28. Wang Y, Zheng Y, Chen J, Wu H, Zheng D and Hui R: A novel epithelial sodium channel gamma-subunit de novo frameshift mutation leads to Liddle syndrome. Clin Endocrinol (Oxf) 67: 801-804, 2007.

29. Zhou R, Patel SV and Snyder PM: Nedd4-2 catalyzes ubiquitination and degradation of cell surface ENaC. J Biol Chem 282: 20207-20212, 2007.

30. Sabbadin C and Fallo F: Hyperaldosteronism: Screening and dagnostic tests. High Blood Press Cardiovasc Prev 23: 69-72, 2016.

31. Ding X: A review for the reasons of hypertension and hypokelamia. Chin J Gen Pract 1: 4, 2015 (In Chinese).

32. Bhimji SS and Sinha V: Adrenal, congenital hyperplasia. In: StatPearls StatPearls Publishing. StatPearls Publishing LLC, Treasure Island (FL), 2018

33. El-Maouche D, Arlt W and Merke DP: Congenital adrenal hyperplasia. Lancet 390: 2194-2210, 2017.

34. Funder JW: Apparent mineralocorticoid excess. J Steroid Biochem Mol Biol 165: 151-153, 2017.

35. Yaxley J and Pirrone C: Review of the Diagnostic Evaluation of Renal Tubular Acidosis. Ochsner J 16: 525-530, 2016. 